\title{
Study on the Thermal Properties of Hollow Shale Blocks as Self-Insulating Wall Materials
}

\author{
Guo-liang Bai, Ning-jun Du, Ya-zhou Xu, and Chao-gang Qin \\ School of Civil Engineering, Xi'an University of Architecture and Technology, Shaanxi 710055, China \\ Correspondence should be addressed to Ning-jun Du; duningjun@live.xauat.edu.cn
}

Received 16 August 2016; Accepted 26 April 2017; Published 1 June 2017

Academic Editor: Wei Zhou

Copyright (C) 2017 Guo-liang Bai et al. This is an open access article distributed under the Creative Commons Attribution License, which permits unrestricted use, distribution, and reproduction in any medium, provided the original work is properly cited.

\begin{abstract}
To reduce energy consumption and protect the environment, a type of hollow shale block with 29 rows of holes was designed and produced. This paper investigated the thermal properties of hollow shale blocks and walls. First, the guarding heat-box method was used to obtain the heat transfer coefficient of the hollow shale block walls. The experimental heat transfer coefficient is $0.726 \mathrm{~W} / \mathrm{m}^{2} \cdot \mathrm{K}$, which would save energy compared to traditional wall materials. Then, the theoretical value of the heat transfer coefficient was calculated to be $0.546 \mathrm{~W} / \mathrm{m}^{2} \cdot \mathrm{K}$. Furthermore, the one-dimensional steady heat conduction process for the block and walls was simulated using the finite element analysis software ANSYS. The predicted heat transfer coefficient for the walls was $0.671 \mathrm{~W} / \mathrm{m}^{2} \cdot \mathrm{K}$, which was in good agreement with the test results. With the outstanding self-insulation properties, this type of hollow shale block could be used as a wall material without any additional insulation measures in masonry structures.
\end{abstract}

\section{Introduction}

Worldwide, economic development has been increasingly restricted by a shortage of natural resources [1]. Furthermore, economic growth results in problems such as destruction of the environment and resource waste. To improve this situation and to promote building energy efficiency, the traditional solid clay bricks have been officially forbidden in building construction, promoting the study and application of new wall materials [2].

Currently, there are many types of new wall materials, such as small concrete hollow block, aerated concrete block, and small hollow fly ash block. However, none of these wall materials are self-insulating, and certain external wall thermal insulation measures are required. External insulation measures for exterior walls are widely used in construction despite some obvious shortcomings such as easily falling off, short service life, and low safety. Furthermore, in traditional brick masonry, the thickness of mortar joints varies from $8 \mathrm{~mm}$ to $12 \mathrm{~mm}$, easily forming obvious thermal bridges and resulting in significant energy loss.

Over the past 40 years, a variety of insulation sintered hollow blocks have been developed, such as those proposed by Porothem, Klimation, Poroton, Thermopor, Unipor,
Monomur, and Thermoarcilla [3]. All of these blocks have the merits of low density, high hole rate, high surface smoothness, and good thermal performance. Zhu et al. [4] investigated the thermal properties of recycled aggregate concrete (RAC) and recycled concrete blocks. Sodupe-Ortega et al. [5] manufactured a type of rubberized long hollow block and studied the technical and economic feasibility of producing these blocks using automated brick machines. Zhang et al. [6] studied the thermal performance of concrete hollow blocks using FEM simulations. Fan et al. [7] described a new building material named expanded polystyrene recycled concrete and conducted corresponding numerical simulations for hollow EPSRC blocks and thermally insulating walls based on thermodynamic principles. In recent works, numerical simulation methods have been proposed by Del Coz Díaz et al. [8-11] for studying various types of walls made of different light concrete hollow bricks. Li et al. [12] presented the development of a simplified heat transfer model of hollow blocks for simple and efficient heat flow calculation.

Hollow shale block consists of shale as the main raw material, sawdust as the pore-forming agent, and industrial wastes such as fly ash, steel slag, and wastepaper chips as auxiliary materials. All of these raw materials are fired following a certain production process to make a new energy-saving 

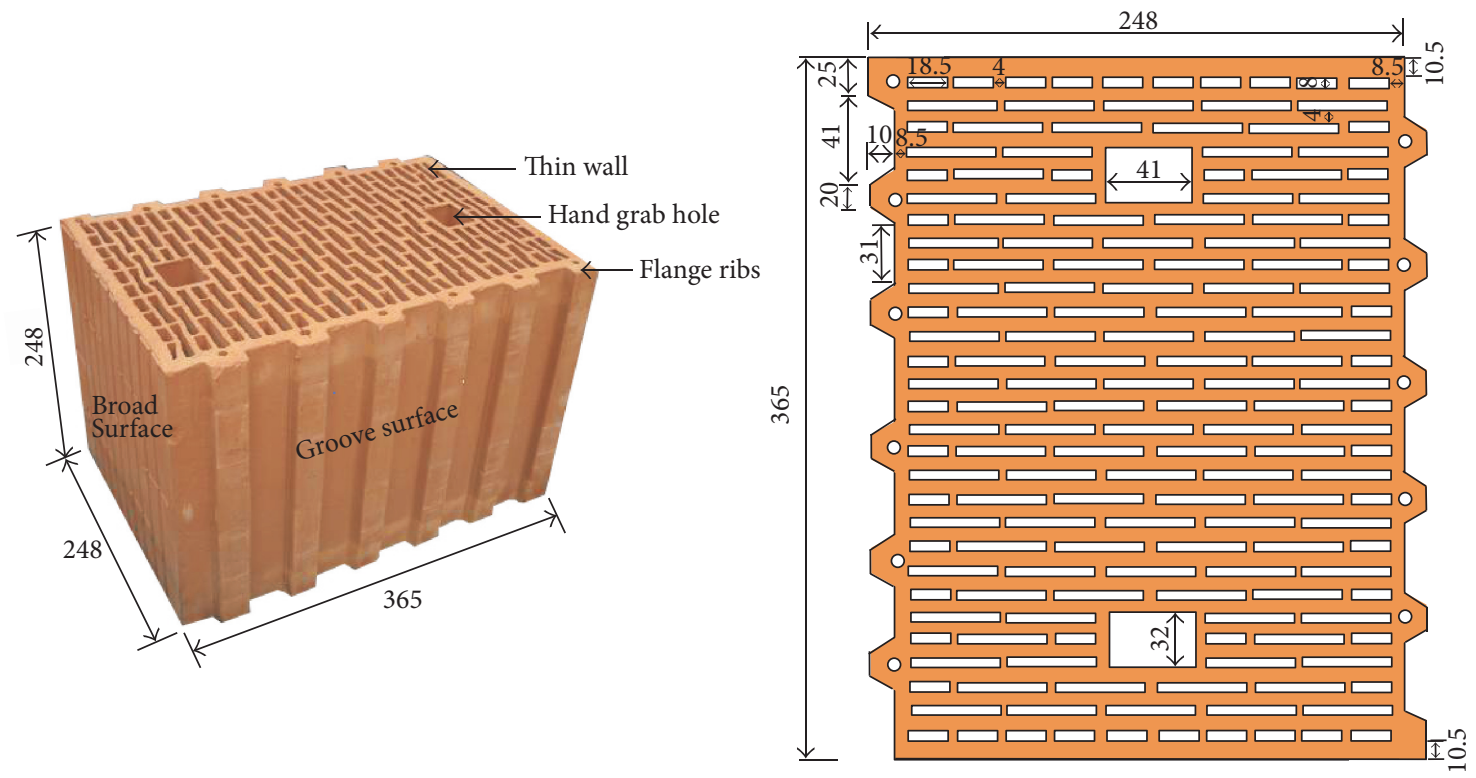

FIGURE 1: Detailed dimensions of a hollow shale block (in mm).

and environmentally friendly wall material that has the advantages of light weight, large size, high hole rate, and high smoothness. Meanwhile, hollow shale blocks make full use of the abundant shale resources to save farmland. During the process of building walls with hollow shale blocks, a mortar joint construction technology with a thickness of 1 $2 \mathrm{~mm}$ is developed to significantly reduce the heat loss caused by structural thermal bridges. Excellent thermal insulation properties and energy efficiency of residential buildings in severe cold and cold areas are expected to be achieved in external walls without external insulation measures. $\mathrm{Wu}$ et al. [13] investigated the mechanical and thermal properties of fired hollow block walls. Bai et al. $[14,15]$ studied the seismic behavior of fired heat-insulated shale block walls with ultrathin mortar joints.

The heat transfer coefficient is one of the most important parameters for evaluating the thermal performance of walls. For a specified ambient temperature, the lower the heat transfer coefficient is, the less the heat dissipated through the wall is. Currently, the heat transfer coefficients of walls are mainly determined by on-site measurements or lab testing [16]. In this study, the heat transfer coefficients of hollow shale block walls were obtained from lab testing and compared with the theoretical calculation and finite element simulation results. Section 2 presents detailed dimensions, production procedures, chemical components, and mineral composition of the hollow shale block.

\section{Hollow Shale Block}

2.1. Details of the Hollow Shale Block. The dimensions of the blocks are $365 \mathrm{~mm} \times 248 \mathrm{~mm} \times 248 \mathrm{~mm}$ with 29 rows of holes; the density is $850 \mathrm{~kg} / \mathrm{m}^{3}$, which could significantly
TABLE 1: Chemical composition of shale.

\begin{tabular}{lc}
\hline Chemical constituents & Content (wt\%) \\
\hline $\mathrm{SiO}_{2}$ & 62.91 \\
$\mathrm{Al}_{2} \mathrm{O}_{3}$ & 17.01 \\
$\mathrm{Fe}_{2} \mathrm{O}_{3}$ & 6.83 \\
$\mathrm{CaO}$ & 6.13 \\
$\mathrm{MgO}$ & 2.78 \\
$\mathrm{~K}_{2} \mathrm{O}$ & 1.88 \\
$\mathrm{Na}_{2} \mathrm{O}$ & 1.04 \\
$\mathrm{SO}_{3}$ & 0.65 \\
$\mathrm{TiO}_{2}$ & 0.77 \\
\hline
\end{tabular}

reduce the building weight and improve the heat insulation efficiency of the blocks. The detailed dimensions are shown in Figure 1.

\subsection{Raw Materials}

2.2.1. Shale. Shale is an ancient sedimentary rock that was formed through long-term geological processes. Ancient rocks are broken into clay minerals and a small amount of clastic minerals through weathering and are then transported to the sedimentary location in a state of suspension. All of these minerals are deposited mechanically and became clay rocks with a lamellation structure under low temperature and low pressure due to external forces and the diagenesis effect. In China, more than $75 \%$ of the land surface is covered by sedimentary rocks, of which shale represents $77.5 \%$ [17].

The chemical composition of shale is shown in Table 1; the main mineral components of shale are quartz, calcite, 


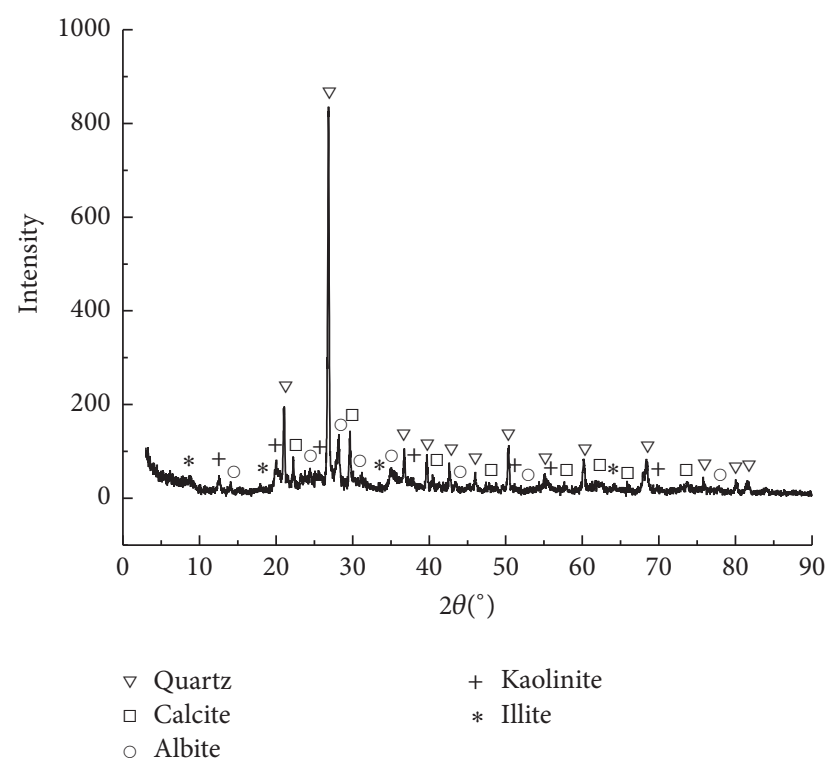

FIgURE 2: XRD spectrum of shale.

sodium feldspar, kaolinite, and illite. The corresponding XRD spectrum is shown in Figure 2. After mining, crushing, and fine grinding, shale is one of the most promising new wall materials to replace sintered clay brick due to its abundant storage quantities and easy mining.

2.2.2. Pore-Forming Agent. The function of the pore-forming agent is to produce a large number of pores during the sintering process to take advantage of the lower thermal conductivity coefficient of air. Therefore, the pore-forming agent can effectively enhance the insulation performance of hollow shale blocks and reduce their weight, which improves the seismic performance. Considering energy conservation, resource recycling, and environmental protection, sawdust was selected as the pore-forming agent for the hollow shale blocks. As the scrap material of wood processing, sawdust has many advantages when used as the pore-forming agent. Sawdust is mainly made of plant fiber that is stable, and loss on ignition can be as high as $98.49 \%$. The pore-forming can generate many pores inside blocks and enhance the thermal insulation property. In addition, sawdust is also plentiful, cheap, and easy to obtain.

2.2.3. Industrial Wastes. Fly ash, steel slag, and waste paper chips were added during the sintering process as auxiliary materials.

2.3. Production Procedure. As a new type of energy-saving wall material, the production process of hollow shale blocks includes grinding, aging, stirring, extrusion, incision, drying, setting, and high temperature sintering. Most of the processes are automated. The production process of hollow shale blocks is illustrated in Figure 3.

\section{Experimental Details}

To verify the applicability of the hollow shale blocks, the thermal performance testing of the masonry walls was conducted in accordance with Chinese codes [18].

3.1. Specimens. Test walls with dimensions of $1650 \mathrm{~mm} \times$ $1650 \mathrm{~mm} \times 365 \mathrm{~mm}$ (length $\times$ height $\times$ width) were built using the hollow shale blocks (see Figure 4).

The void ratio of a hollow shale block is as high as $54 \%$, and its compression strength grade reaches $10 \mathrm{MPa}$. In addition, its honeycomb mesh structure can provide excellent thermal insulation performance. Three specimens were built, and the horizontal mortar joint thickness ranged from $1 \mathrm{~mm}$ to $2 \mathrm{~mm}$. Because there was no vertical mortar joint in the test walls, tongue-and-groove connections were used to interlock and strengthen the hollow shale block walls. After the specimens had been fully dried with maintenance for 20 days, the thermal performance was tested.

3.2. Test Apparatus. The schematic of the steady-state heat transfer performance test device is shown in Figure 5, which was designed according to Chinese code GB/T13475-2008 [18] and the guarding heat-box method, as illustrated in Figure 6.

Because the protection box in the guarding heat-box method encircles the metering box, the heat flux through the metering box wall $\left(Q_{3}\right)$ and the heat flux of the flanking loss $\left(Q_{2}\right)$ can be reduced to negligible levels if the internal air temperatures of the protection box and metering box are equal. Theoretically, if a homogeneous specimen is installed in the device whose inside and outside temperatures are uniform, the specimen's surface temperature will be at steady state. In other words, the heat flux through the metering box walls would be equal to the heat flux of the flanking loss $\left(Q_{2}=\right.$ $\left.Q_{3}=0\right)$. However, the heat transfer coefficient of a real homogeneous specimen is always uneven, especially for the parts near the edges of the metering box. Therefore, the surface temperatures of the specimens and close to the metering box are uneven, and the heat flux through the metering box wall $\left(Q_{3}\right)$ and the heat flux of the flanking loss $\left(Q_{2}\right)$ cannot actually be reduced to zero. In the present work, $Q_{2}$ and $Q_{3}$ can be obtained using the standard calibration test. Furthermore, the heat transfer coefficient $K$ can be calculated using

$$
\begin{aligned}
Q_{1} & =Q_{P}-Q_{3}-Q_{2} \\
R & =\frac{A\left(T_{s i}-T_{s e}\right)}{Q_{1}} \\
K & =\frac{Q_{1}}{A\left(T_{n i}-T_{n e}\right)} .
\end{aligned}
$$

Eq. (1) includes the following variables: thermal power inlet $Q_{P}$, heat flux through the specimen $Q_{1}$, surface temperature on the warm side $T_{s i}$, surface temperature on the cold side $T_{s e}$, air temperature on the warm side $T_{n i}$, air temperature on the cold side $T_{n e}$, surface area of the specimen $A$, and thermal resistance $R$. 
TABLE 2: Thermal parameters of the hollow shale block walls.

\begin{tabular}{lccc}
\hline Specimens & $\begin{array}{c}\text { Heat transfer coefficient } \\
K\left(\mathrm{~W} / \mathrm{m}^{2} \cdot \mathrm{K}\right)\end{array}$ & $\begin{array}{c}\text { Thermal resistance } \\
R\left(\mathrm{~m}^{2} \cdot \mathrm{K} / \mathrm{W}\right)\end{array}$ & $\begin{array}{c}\text { Total thermal resistance } \\
R_{u}\left(\mathrm{~m}^{2} \cdot \mathrm{K} / \mathrm{W}\right)\end{array}$ \\
\hline $\mathrm{A}$ & 0.751 & 1.275 & 1.332 \\
$\mathrm{~B}$ & 0.726 & 1.080 & 1.377 \\
$\mathrm{C}$ & 0.703 & 1.342 & 1.422 \\
Mean & 0.726 & 1.232 & 1.377 \\
\hline
\end{tabular}

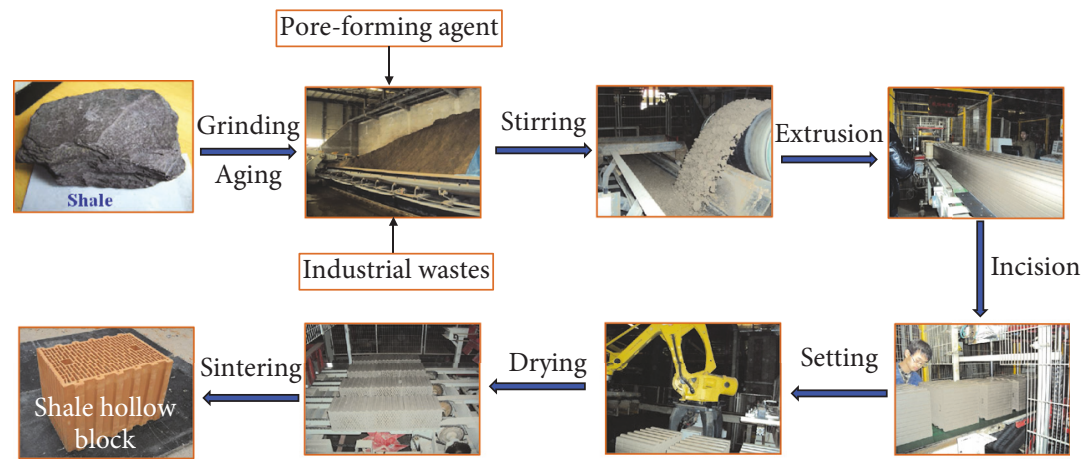

FIGURE 3: Production procedure for hollow shale blocks.

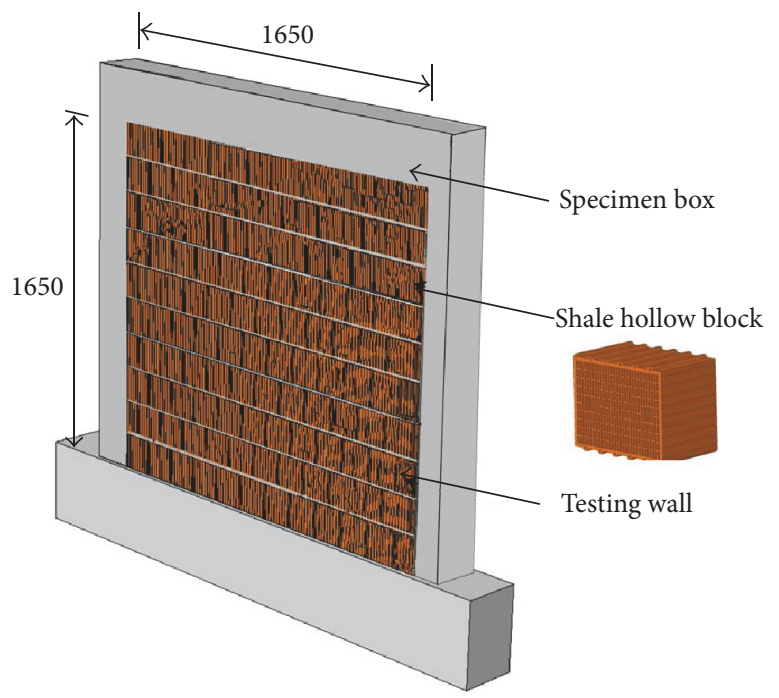

FIGURE 4: Details of the test wall.

\subsection{Testing Procedure}

(1) After 20 days of natural air drying, the specimens were installed in the test machine. The seam crossing parts between the specimen and the specimen box were filled with a foaming insulation agent for sealing, as shown in Figure 7(a).

(2) The length of the locating rods connected to the temperature sensors inside the cold box and heat metering box were checked and adjusted, as shown in Figure 7(b).

(3) After the test machine had run for more than 20 hours for each specimen and the range of heating power values was between $0.5 \mathrm{~W}$ and $3 \mathrm{~W}$, the whole system could be regarded to be at a thermal steady state. Then, the measured data were collected every half hour, and the average value of the test results was calculated.

3.4. Experimental Results and Discussion. Based on the test results of the three hollow shale block walls, thermal parameters such as the heat transfer coefficient, thermal resistance, and total thermal resistance were calculated and are listed in Table 2 .

The results indicate that the heat transfer coefficient of hollow shale block walls is $0.726 \mathrm{~W} /\left(\mathrm{m}^{2} \cdot \mathrm{K}\right)$, which meets the 
TABLE 3: Comparison with other wall materials.

\begin{tabular}{lccc}
\hline Wall material & $\begin{array}{c}\text { Heat transfer coefficient } \\
K\left(\mathrm{~W} / \mathrm{m}^{2} \cdot \mathrm{K}\right)\end{array}$ & $\begin{array}{c}\text { Thermal resistance } \\
R\left(\mathrm{~m}^{2} \cdot \mathrm{K} / \mathrm{W}\right)\end{array}$ & Dimensions \\
\hline Hollow shale block & 0.726 & 1.232 & $365 \mathrm{~mm} \times 248 \mathrm{~mm} \times 248 \mathrm{~mm}$ with 29 rows of holes \\
Clay brick & 2.240 & 0.296 & $240 \mathrm{~mm} \times 115 \mathrm{~mm} \times 53 \mathrm{~mm}$ \\
Concrete block & 2.220 & 0.300 & $390 \mathrm{~mm} \times 190 \mathrm{~mm} \times 190 \mathrm{~mm}$ with three rows of holes \\
Recycled concrete blocks & 1.620 & 0.457 & $390 \mathrm{~mm} \times 240 \mathrm{~mm} \times 190 \mathrm{~mm}$ with three rows of holes \\
\hline
\end{tabular}

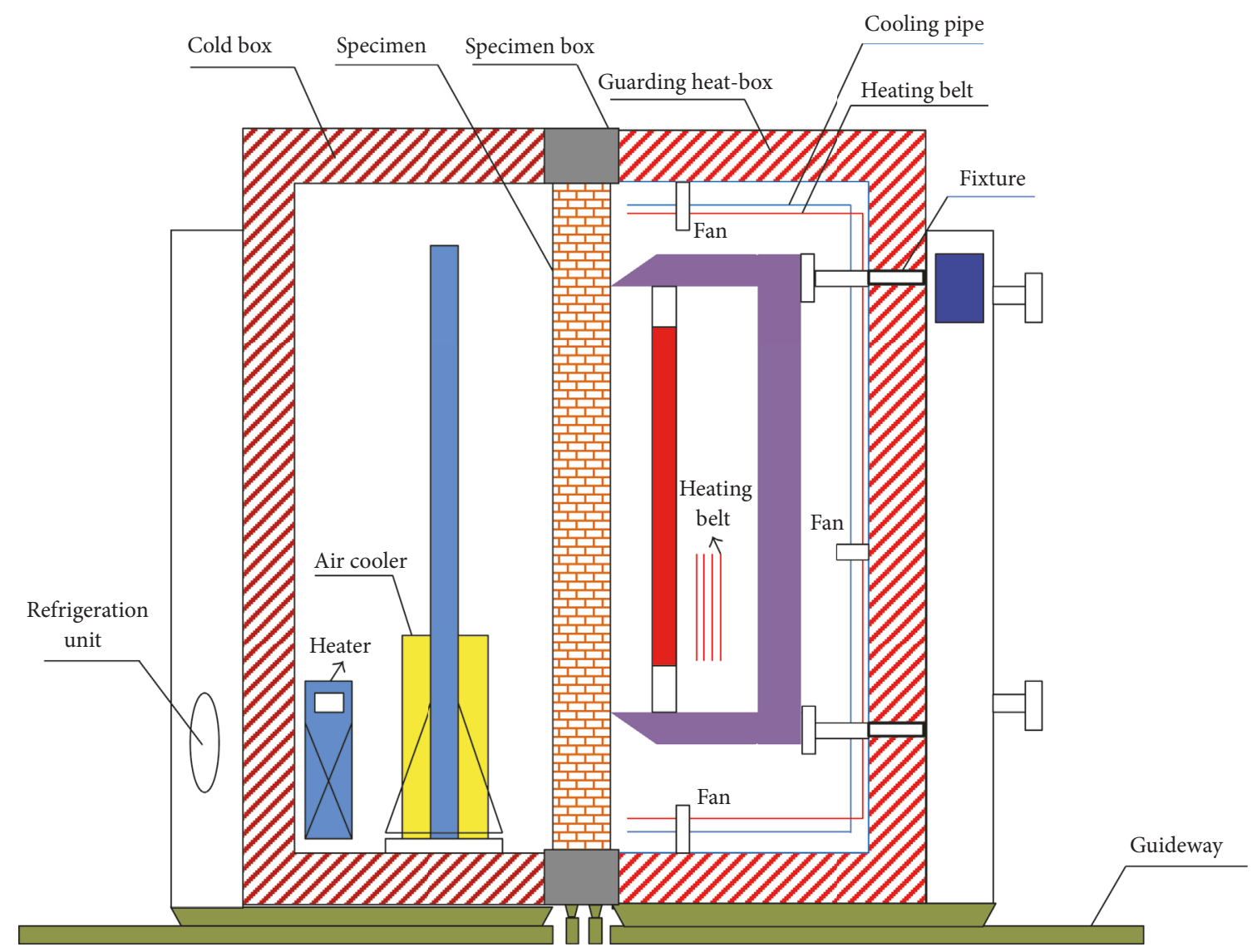

FIGURE 5: Schematic of the test machine for steady-state heat transfer.

design standard for the energy efficiency of public buildings in GB50189-2005 [19].

Heat transfer coefficient $K$ and thermal resistance $R$ of different wall materials which are measured by the same equipment and same testing methods are shown in Table 3 according to the research of Yang et al. [20] and Wu et al. [13] and technical specification for concrete small-sized hollow block masonry buildings of China JGJ/T2011 [21]. The heat preservation effect of the hollow shale block walls is 3.16 times higher than that of traditional clay brick walls, 3.11 times higher than that of concrete block walls, and 1.69 times higher than that of recycled concrete blocks walls. As a building envelope material, hollow shale blocks can not only improve the heat preservation and heat insulation performance of buildings but also make the indoor thermal environment more comfortable, especially in cold regions.

\section{Theoretical Calculation of the Heat Transfer Coefficient of Hollow Shale Block Walls}

Building envelopes can be categorized as single-layer walls, multilayer walls, and combination walls according to their composition. A multilayer wall, such as a double-sided plastered brick wall, is composed of several layers of different wall materials along the direction of heat flow. The total thermal resistance of a multilayer wall is the sum of the thermal resistance of each single-layer wall. Assuming that the heat transfer is a one-dimensional steady heat transfer 
TABLE 4: Thermal parameters of hollow shale block walls.

\begin{tabular}{lccccccc}
\hline Area number & 1,21 & $2,4,6,8,14,16,18,20$ & $3,7,15,19$ & 5,17 & 9,13 & 10,12 & 11 \\
\hline$F_{i}(\mathrm{~mm})$ & $14 \times 248$ & $18.5 \times 248$ & $4 \times 248$ & $4 \times 248$ & $4 \times 248$ & $18.5 \times 248$ & $4 \times 248$ \\
$R_{0}$ & 0.938 & 3.317 & 2.976 & 2.074 & 1.568 & 3.082 & 1.767 \\
\hline
\end{tabular}

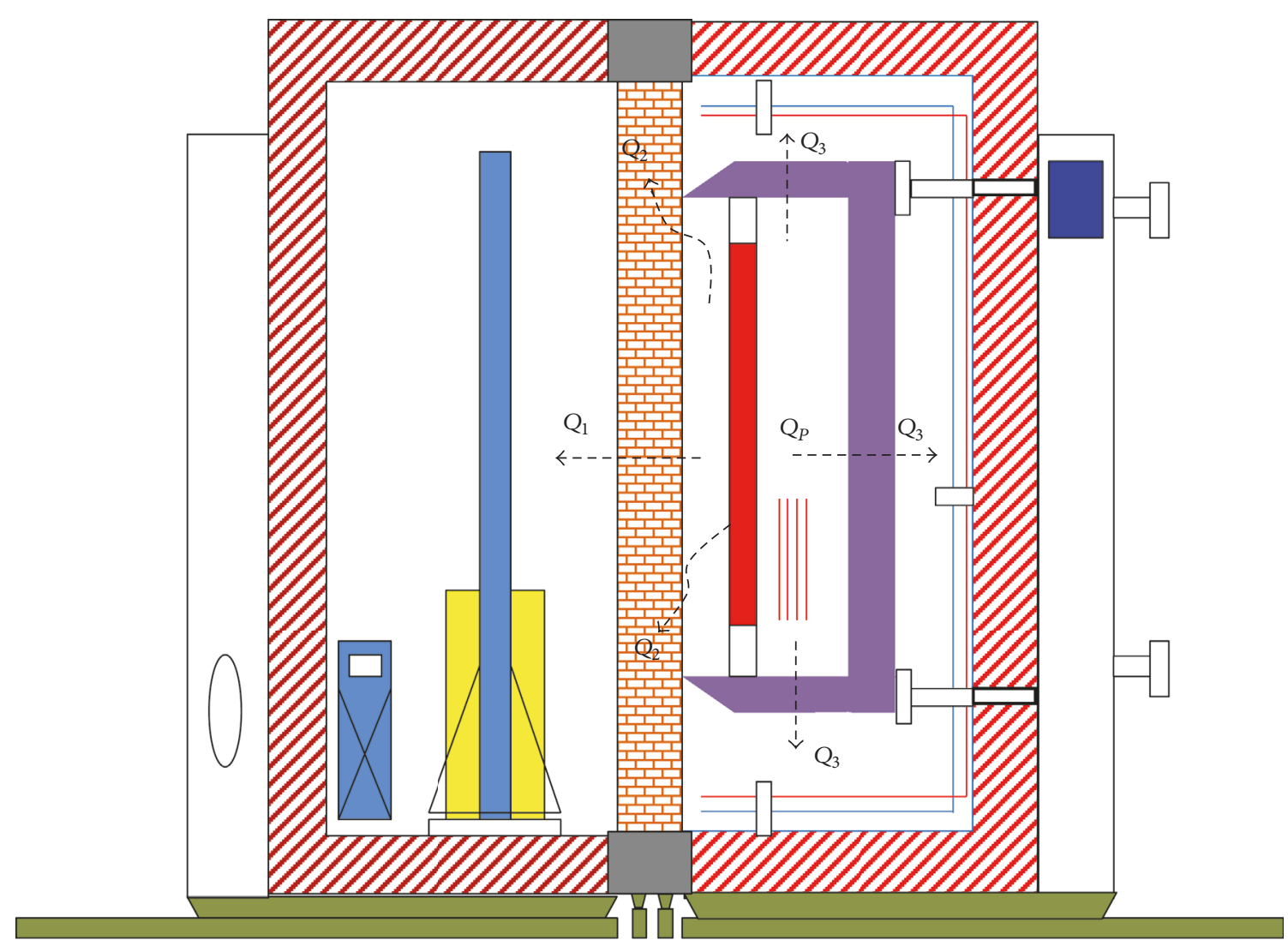

Figure 6: Illustration of the test theory.

process, the multilayer wall parallel to the direction of heat flow can be divided into several areas whose interfaces are determined according to the material layer composition [22]. The average thermal resistance of a multilayer wall can be calculated as follows [18]:

$$
\bar{R}=\left[\frac{F_{0}}{F_{1} / R_{0,1}+F_{2} / R_{0,2}+\cdots+F_{n} / R_{0, n}}\left(R_{i}+R_{e}\right)\right] \varphi,
$$

where $\bar{R}$ is the average thermal resistance, $F_{0}$ is the total heat transfer area perpendicular to the direction of heat flow, $\varphi$ is a correction factor, which is 0.86 for hollow shale block, $F_{1}, F_{2}, \ldots, F_{n}$ are the divided areas parallel to the direction of heat flow, $R_{0,1}, R_{0,2}, \ldots, R_{0, n}$ are the thermal resistances of heat transfer surfaces, $R_{i}$ is the thermal resistance of the inner surface, which is $0.11 \mathrm{~m}^{2} \cdot \mathrm{K} / \mathrm{W}$, and $R_{e}$ is the thermal resistance of the outer surface, which is $0.04 \mathrm{~m}^{2} \cdot \mathrm{K} / \mathrm{W}$ [18].

Hollow shale blocks with 29 rows of holes are multilayer walls. Their average thermal resistance can be calculated using the method mentioned above. For convenience, the tongue-and-grooves on the side surfaces are neglected. The detailed area division is illustrated in Figure 8.
The total heat transfer surface of a hollow shale block perpendicular to the direction of heat flow is divided into 21 areas. All of these heat transfer areas are multilayer except for areas 1 and 2 . The thermal conductivity of sintered shale material is $0.463 \mathrm{~W} /(\mathrm{m} \cdot \mathrm{K})$, the thermal resistance of an $8 \mathrm{~mm}$ air layer is $0.12 \mathrm{~m}^{2} \cdot \mathrm{K} / \mathrm{W}$, and the thermal resistance of a $32 \mathrm{~mm}$ air layer is $0.17 \mathrm{~m}^{2} \cdot \mathrm{K} / \mathrm{W}$. The results of the thermal resistance calculation are listed in Table 4.

The average thermal resistance of hollow shale blocks can be obtained using (2): $\bar{R}=1.688 \mathrm{~m}^{2} \cdot \mathrm{K} / \mathrm{W}$. The average heat transfer coefficient can be obtained as follows:

$$
K_{0}=\frac{1}{R_{i}+\bar{R}+R_{e}}=0.544\left(\mathrm{~W} / \mathrm{m}^{2} \cdot \mathrm{K}\right) .
$$

Assuming that the thickness of the horizontal mortar is $2 \mathrm{~mm}$ and taking a block and a horizontal mortar joint as the typical unit, the heat transfer coefficients is

$$
K=\frac{K_{0} A_{0}+K_{1} A_{1}}{A_{0}+A_{1}}=0.546\left(\mathrm{~W} / \mathrm{m}^{2} \cdot \mathrm{K}\right),
$$




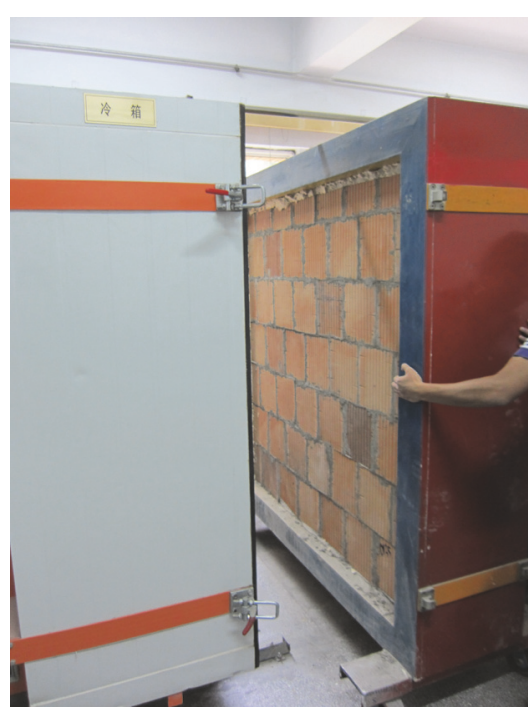

(a)

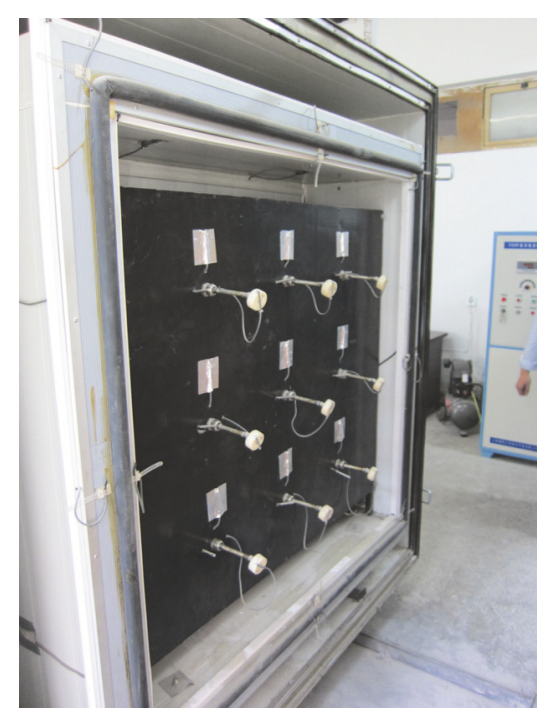

(b)

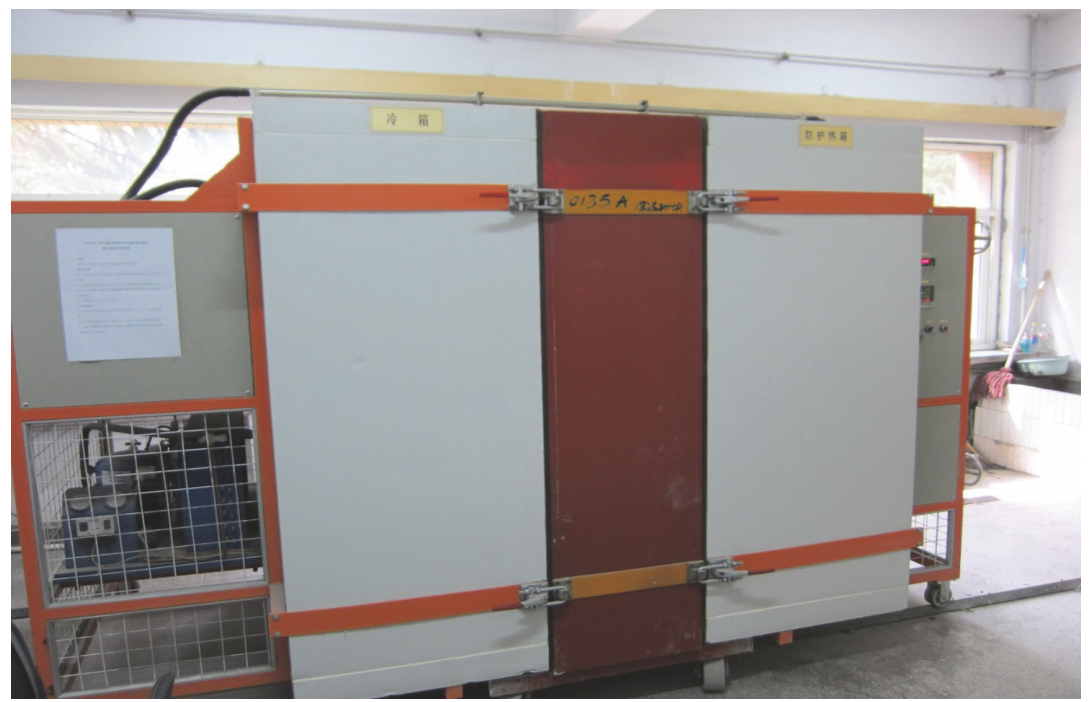

(c)

FIgURE 7: Testing procedure.

where $A_{0}$ and $A_{1}$ are the lateral areas of the hollow shale block and mortar joint, respectively, and $K_{0}$ and $K_{1}$ are the heat transfer coefficients of the hollow shale blocks and mortar joint, respectively. Compared with the experimental test results, the theoretical calculated values of $K_{0}$ and $K$ of the hollow shale blocks are smaller due to the simplification on both sides of the hollow shale block.

\section{Numerical Simulation Using the Finite Element Method}

5.1. FEM Model. To provide an alternative thermal analysis and design of the hollow shale block, an FEM model using the three-dimensional thermal element SOLID70 was developed using the ANSYS package, as shown in Figure 9.

Considering the thermal resistance effect between air layers, the holes in the blocks were treated as solid elements with the parameters of the air interlayer property. The heat flow between different materials was regarded as a continuous process. According to the temperatures of the hot chamber and the cold chamber, the heat transfer coefficient and temperature loads were defined on the surfaces of the blocks. The internal surface temperature is $30^{\circ} \mathrm{C}$, and the external surface temperature is $-10^{\circ} \mathrm{C}$.

In fact, parameters for FEM simulation are crucial to reasonable calculation results. In present FEM models, values of the parameters needed to be given were set based on the thermal design code for civil building of China [23]. The convective heat transfer coefficients of the inner surface (guarding heat-box) and outer surface (cold box) of the hollow shale block wall are $8.7 \mathrm{~W} /\left(\mathrm{m}^{2} \cdot \mathrm{K}\right)$ and $23.0 \mathrm{~W} /\left(\mathrm{m}^{2} \cdot \mathrm{K}\right)$, respectively. The thermal conductivity of sintered shale material is $0.463 \mathrm{~W} /(\mathrm{m} \cdot \mathrm{K})$, the thermal conductivity of an $8 \mathrm{~mm}$ air layer is $0.067 \mathrm{~W} /(\mathrm{m} \cdot \mathrm{K})$, and the thermal conductivity of a 


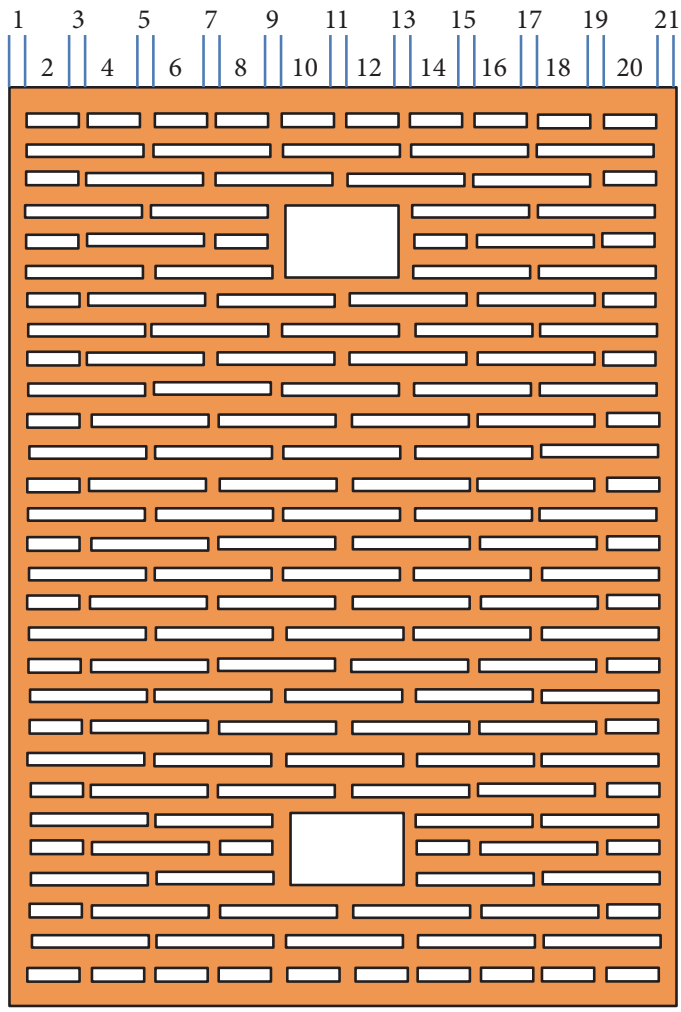

Figure 8: Area division of a hollow shale block.

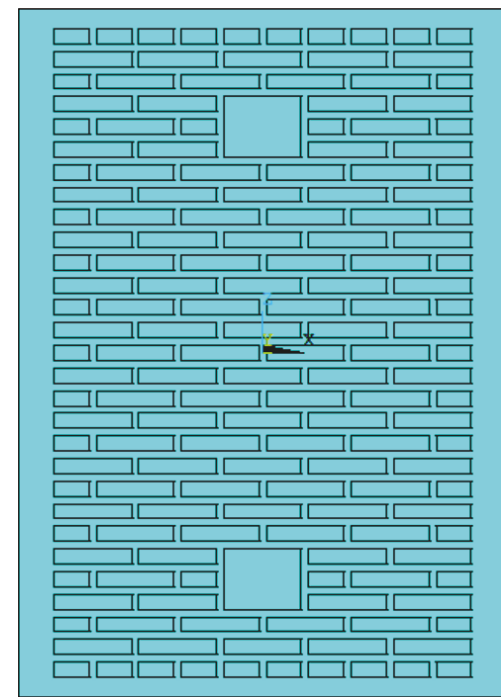

29 brick model

(a) FEM model of the block

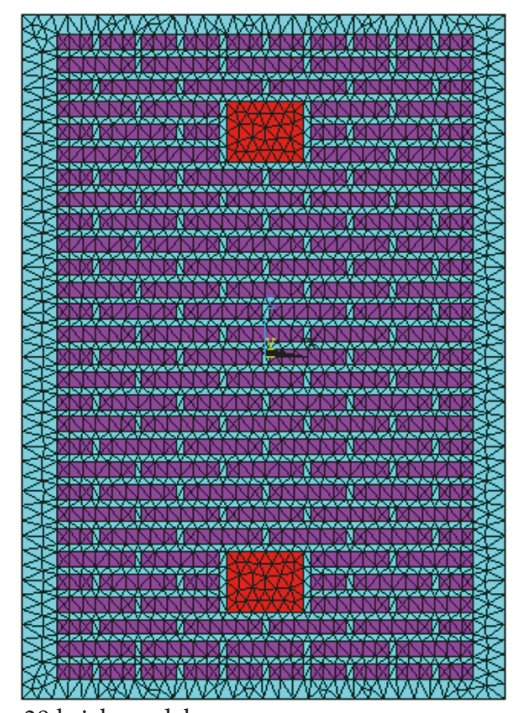

29 brick model

(b) Mesh generation of the block

FIGURE 9: FEM model of the hollow shale block.

$32 \mathrm{~mm}$ air layer is $0.188 \mathrm{~W} /(\mathrm{m} \cdot \mathrm{K})$. The thermal conductivity of the mortar is $0.339 \mathrm{~W} /(\mathrm{m} \cdot \mathrm{K})$.

Because there is no vertical mortar joint, the influence of the vertical connections can be neglected in the FEM model. The vertical joint between shale blocks was symmetrical, and the symmetry plane was considered to be an adiabatic boundary, meaning that there was no heat exchange on either side of the symmetry plane. The corresponding FEM meshes and loading process of the walls are shown in Figure 10, in which the boundary conditions and temperature simulation are the same as those of the shale block.

5.2. Simulation Results. The simulated temperature field and heat flow density for the hollow shale block are shown in 


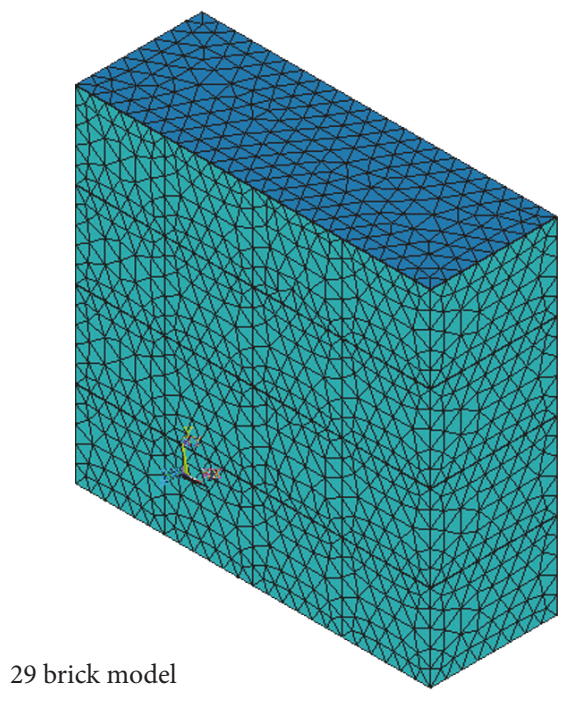

(a)

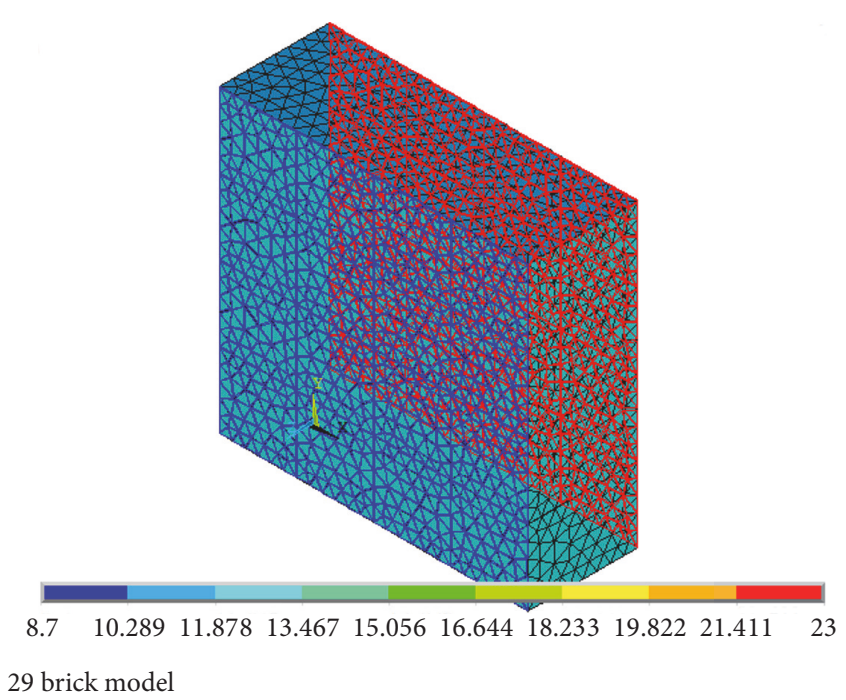

(b)

Figure 10: FEM meshes (a) and loading process (b) for the hollow shale block wall.

Figure 11. It is observed that the temperature distribution in the block varies linearly along the direction of heat flow and is distributed uniformly. The heat flux density and temperature gradient of the hollow shale block gradually increase from outside to inside. The heat flux density and temperature gradient are small for the air interlayer inside the block but larger on the rib between air interlayers along the direction of heat flow. In addition, the most heat dissipation per unit area occurs in the ribs of the hollow shale block. It is easy to determine that the internal air layer is beneficial for prevent the heat loss.

Figure 12 displays the simulation results of the hollow shale block wall. In the vertical junction of two blocks, there is no air interlayer along the direction of heat flow, especially around the edges of the blocks, where the heat flow is strong and the temperature gradient significantly changes. Conversely, the heat flow is small and the change in the temperature gradient is not as large on the horizontal mortar joints. The heat flux density vector also indicates that there is less heat loss through the horizontal mortar joints. The heat transfer effect of the hollow shale blocks depends on the masonry mortar, the quality of the wall masonry, and the mortar joint thickness. The $2 \mathrm{~mm}$ mortar joints of the hollow shale block wall are sufficiently thin that their influence on the thermal properties can reasonably be neglected.

Although the heat transfer coefficient cannot be directly obtained from the FEM simulation results, it can be calculated based on the following formula:

$$
\begin{aligned}
\lambda & =\frac{q \delta}{\Delta t} \\
\bar{R} & =\frac{\delta}{\lambda} \\
K_{0} & =\frac{1}{R_{i}+\bar{R}+R_{e}},
\end{aligned}
$$

where $q$ is the average value of heat flux, which can be taken from the heat flow density distribution map, $\delta$ is the thickness of the wall, and $\Delta t$ is the temperature difference between the internal and external surfaces of the wall. The heat transfer coefficient of the hollow shale block walls obtained using this method is $0.671 \mathrm{~W} / \mathrm{m}^{2} \cdot \mathrm{K}$, which is less than the experimental value but greater than the theoretical result in Section 4 .

Compared with the experimental results, the theoretical values and FEM simulation results of the heat transfer coefficients of the hollow shale blocks are smaller. The possible reasons for the difference are as follows:

(1) There are cracks on the surface or internal damage formed during transportation of the blocks, which will affect the thermal performance of the masonry wall.

(2) In the process of masonry, when two blocks interlock each other tightly, several closed air layers will emerge between two blocks theoretically. However, due to the deflections of the blocks in the production process, the air layers between two blocks may be interlinked inside and outside the wall which will cause heat loss through this channel and affect the thermal performance of the wall.

Besides the experimental and numerical methods, analytical methods, for example, homogenization method, are alternative ways to investigate the equivalent thermal properties. Homogenization is a quite general strategy which predicts the macrobehavior of a medium based on its microstructures and properties. Masonry structure may be approximately considered as a periodic composite continuum; it is made up of two different materials (brick or block and mortar) arranged in a periodic way. The homogenization theory for periodic media allows the global behavior of masonry to be derived from the behavior of the constitutive materials. So far, the homogenization approach has been used to study the mechanical 


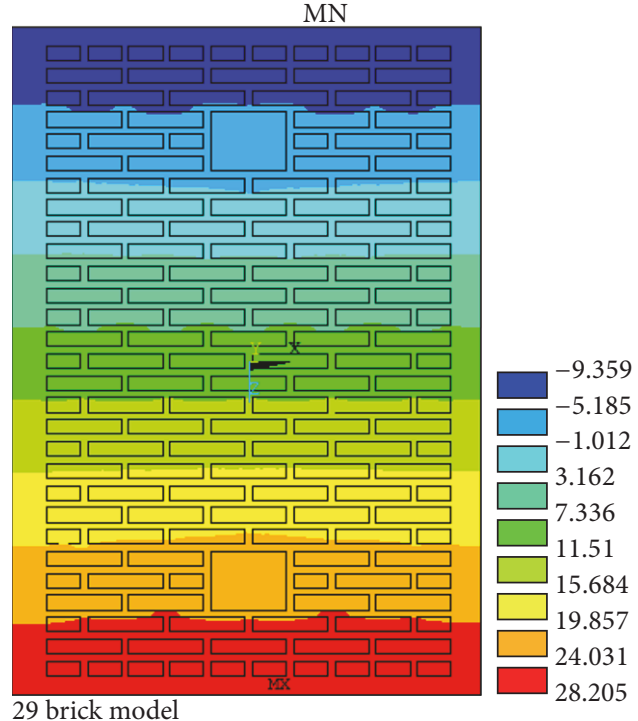

(a) Temperature field distribution

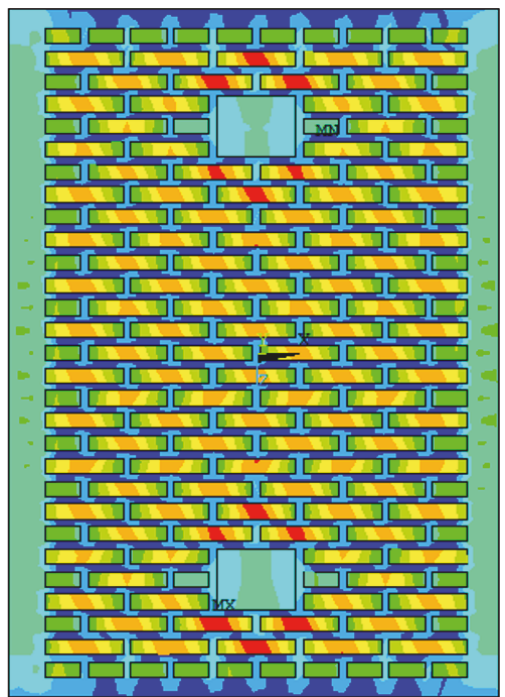

29 brick model

(c) Temperature gradient distribution

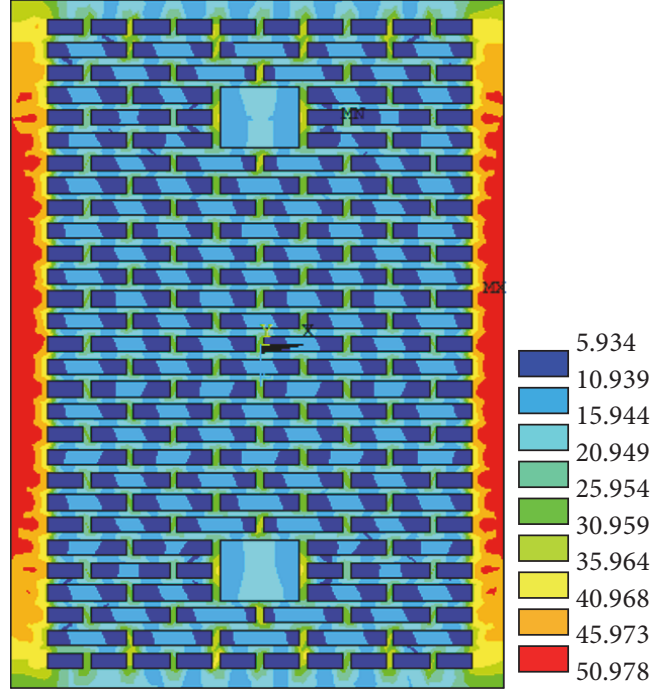

29 brick model

(b) Heat flow density

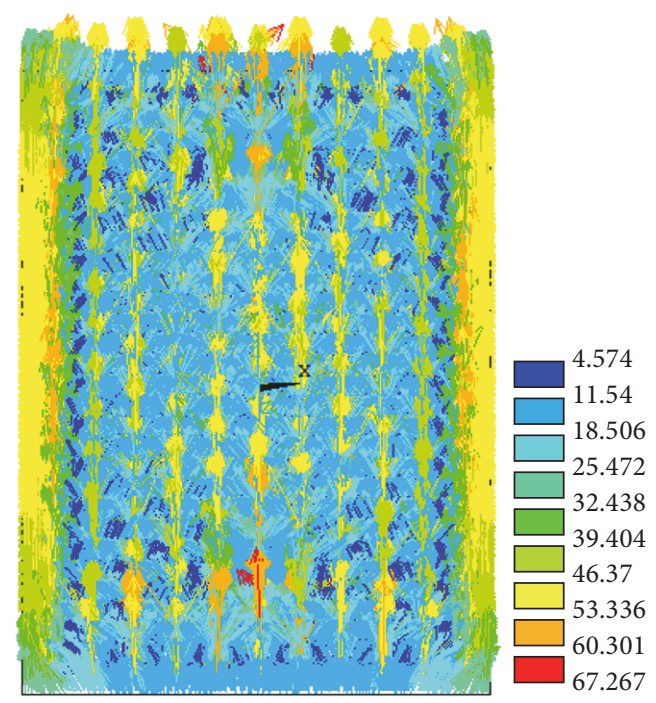

29 brick model

(d) Vector diagram of heat flow density

FIGURE 11: Simulation results for the hollow shale block.

properties of the masonry structure [24-26]. Few researches have been conducted on the thermal properties by this method. In the following studies, it is expected that homogenization strategy could be successively employed to predict the thermal properties of masonry walls staring from thermal properties and compositional structures of block and mortar.

\section{Conclusion}

This study investigates the thermal properties of hollow shale blocks using experimental testing, theoretical calculation, and FEM simulations. The following conclusions can be drawn from this research:

(i) The experimental heat transfer coefficient of hollow shale block walls is $0.726 \mathrm{~W} / \mathrm{m}^{2} \cdot \mathrm{K}$, which meets the design codes and shows their remarkable selfinsulation characteristics compared with other wall materials.

(ii) Using the theoretical formula, the heat transfer coefficient of a single hollow shale block is $0.544 \mathrm{~W} / \mathrm{m}^{2} \cdot \mathrm{K}$, and the heat transfer coefficient of a hollow shale block wall is $0.546 \mathrm{~W} / \mathrm{m}^{2} \cdot \mathrm{K}$. Using the FEM simulation, the heat transfer coefficient of a hollow shale block wall is $0.671 \mathrm{~W} / \mathrm{m}^{2} \cdot \mathrm{K}$. The simplification on both sides of the hollow shale blocks may contribute to the higher experimental heat transfer coefficient.

(iii) The strong heat flow and large temperature gradient mainly appear in the vertical junctions of two blocks because there is no air interlayer along the heat flow 


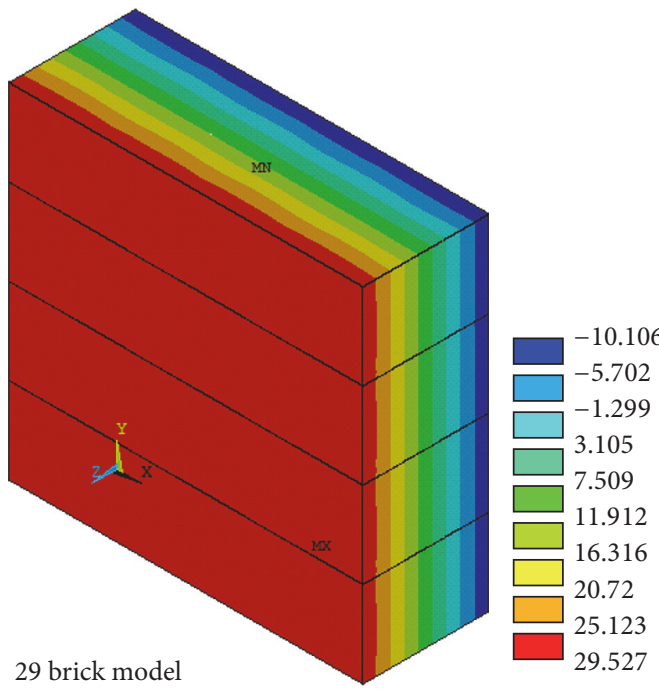

(a) Temperature field distribution

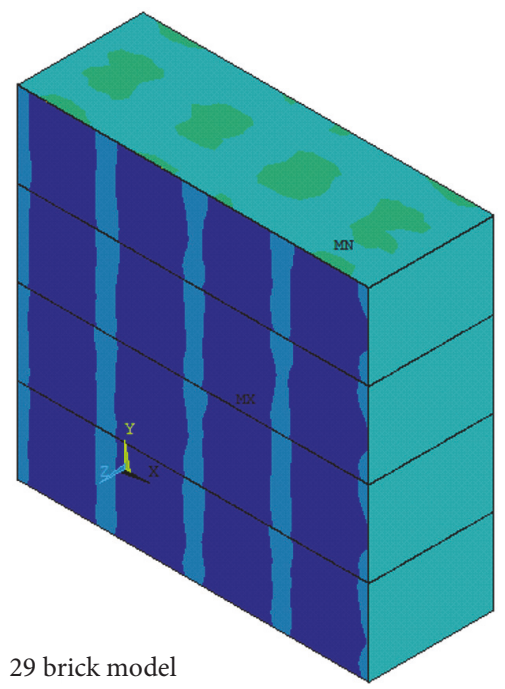

(c) Temperature gradient distribution

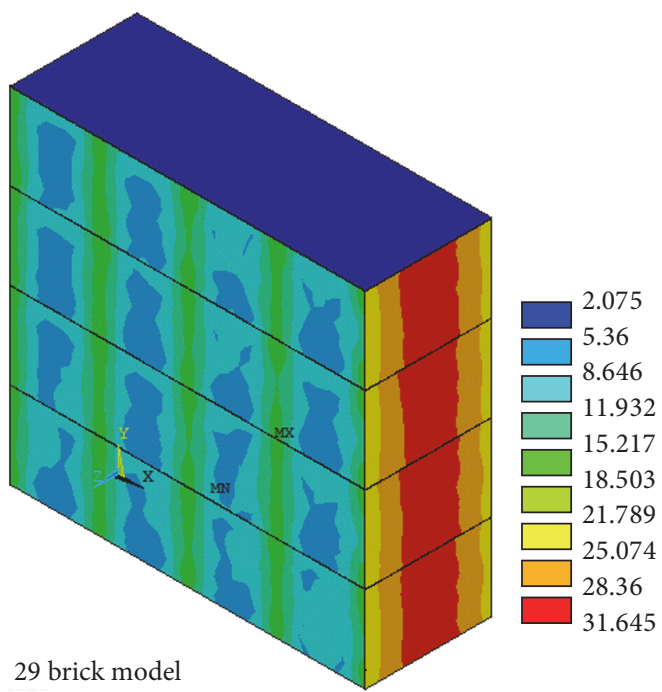

(b) Heat flow density

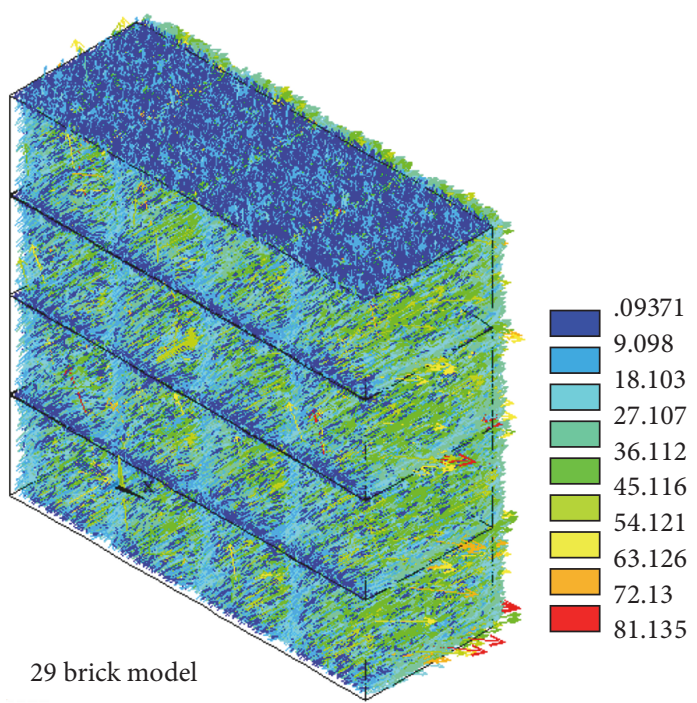

(d) Vector diagram of heat flow density

FIGURE 12: Simulation results for the hollow shale block wall.

direction. The thin mortar joints with a thickness of $2 \mathrm{~mm}$ are beneficial to the strong self-insulation performance of hollow shale block walls.

\section{Conflicts of Interest}

The authors declare that there are no conflicts of interest regarding the publication of this paper.

\section{Acknowledgments}

This research was supported by both the Innovation Team of Xian University of Architecture and Technology and the National Science-Technology Support Plan Projects "EnergySaving Wall Materials Construction Technology Research" and "Cultivating Fund of Excerpts of Dissertation." The support of the Natural Science Foundation of China (Grant nos. 51478381, 51578444) and Key Laboratory Project of Shaanxi Province Education Department (15JS050) is also acknowledged.

\section{References}

[1] W. Lu and Y. Ma, "Image of energy consumption of well off society in China," Energy Conversion and Management, vol. 45, no. 9-10, pp. 1357-1367, 2004.

[2] Ministry of Housing and Urban-rural Development of People's Republic of China, Notification on Further Strengthening of Banning the Use of Solid Clay Brick Work, 2005.

[3] Xian Research \& Design Institute of Wall \& Roof Materials, The feasibility report of the application technologies for energysaving sintering wall materials, 2010 (Chinese). 
[4] L. Zhu, J. Dai, G. Bai, and F. Zhang, "Study on thermal properties of recycled aggregate concrete and recycled concrete blocks," Construction and Building Materials, vol. 94, article no. 6873, pp. 620-628, 2015.

[5] E. Sodupe-Ortega, E. Fraile-Garcia, J. Ferreiro-Cabello, and A. Sanz-Garcia, "Evaluation of crumb rubber as aggregate for automated manufacturing of rubberized long hollow blocks and bricks," Construction and Building Materials, vol. 106, pp. 305316, 2016.

[6] Z. P. Zhang, S. W. Zhu, and G. P. Chen, "Study on thermal performance for straw fiber concrete hollow block," Advanced Materials Research, vol. 953-954, pp. 1596-1599, 2014.

[7] X. S. Fan, Y. L. Chen, X. L. Niu, X. C. Wang, and C. F. Liang, "Numerical analysis on hollow EPSRC block and its thermal insulation wall," Advanced Materials Research, vol. 724-725, pp. 1526-1530, 2013.

[8] J. J. Del Coz Díaz, F. P. Álvarez-Rabanal, O. Gencel et al., "Hygrothermal study of lightweight concrete hollow bricks: a new proposed experimental-numerical method," Journal of Energy and Buildings, vol. 70, pp. 194-206, 2014.

[9] J. J. Del Coz Díaz, P. J. García Nieto, A. M. Rodríguez, A. L. Martínez-Luengas, and C. B. Biempica, "Non-linear thermal analysis of light concrete hollow brick walls by the finite element method and experimental validation," Applied Thermal Engineering, vol. 26, no. 8-9, pp. 777-786, 2006.

[10] J. J. del Coz Díaz, P. J. García Nieto, C. Betegón Biempica, and M. B. Prendes Gero, "Analysis and optimization of the heatinsulating light concrete hollow brick walls design by the finite element method," Applied Thermal Engineering, vol. 27, no. 8-9, pp. 1445-1456, 2007.

[11] J. J. Del Coz Díaz, P. J. García Nieto, J. L. Suárez Sierra, and I. Peñuelas Sánchez, "Non-linear thermal optimization and design improvement of a new internal light concrete multiholed brick walls by FEM," Applied Thermal Engineering, vol. 28, no. 8-9, pp. 1090-1100, 2008.

[12] A. Li, X. Xu, J. Xie, and Y. Sun, "Development of a simplified heat transfer model of hollow blocks by using finite element method in frequency domain," Energy and Buildings, vol. 111, pp. 76-86, 2016.

[13] J. Wu, G.-L. Bai, H.-Y. Zhao, and X. Li, "Mechanical and thermal tests of an innovative environment-friendly hollow block as self-insulation wall materials," Construction and Building Materials, vol. 93, pp. 342-349, 2015.

[14] G. Bai, G. Fu, Z. Quan, H. Wang, and X. Li, "Experimental study on basic mechanical properties of fired heat-insulation hollow block thin mortar joint masonry," Journal of Building Structures, vol. 34, pp. 151-158, 2013.

[15] G. Bai, G. Fu, Z. Quan, H. Wang, and X. Li, "Experimental study on seismic behavior of shale fired heat-insulation block walls with ultra-thin mortar joint," Journal of Building Structures, vol. 10, pp. 111-121, 2014.

[16] J. P. Liu, Building Physics, China Architecture and Building Press, Beijing, China, 2009 (Chinese).

[17] G. Yu, Advantages And Development Direction of Fired Shale Blocks, Brick and Tile World, 2006.

[18] "Thermal insulation-determination of steady-state thermal transmission properties-calibrated and guard hot box. Part 2: device," National Standard GB/T 13475-2008, 2008.

[19] "Energy efficiency of public buildings," National Standard GB50189-2005, 2005.
[20] Z. Yang, F. Zhang, and Z. Quan, “Thermal performance test on the masonry of recycled aggregate concrete block in three rows of holes," Jorunal of Block-Brick-Tile, vol. 6, pp. 37-39, 2012 (Chinese).

[21] "Technical specification for concrete small-sized hollow block masonry buildings of China," Construction Industry Standard JGJ/T2011, 2011.

[22] D. B. Crawley, L. K. Lawrie, F. C. Winkelmann et al., "EnergyPlus: creating a new-generation building energy simulation program," Energy and Buildings, vol. 33, no. 4, pp. 319-331, 2001.

[23] "Thermal design code for civil building of China," National Standard GB50176-93, 1993.

[24] A. Denisiewicz and M. S. Kuczma, "Two-scale numerical homogenization of the constitutive parameters of reactive powder concrete," International Journal for Multiscale Computational Engineering, vol. 12, no. 5, pp. 361-374, 2014.

[25] S. Rastkar, M. Zahedi, I. Korolev, and A. Agarwal, "A meshfree approach for homogenization of mechanical properties of heterogeneous materials," Engineering Analysis with Boundary Elements, vol. 75, pp. 79-88, 2017.

[26] E. Reccia, G. Milani, A. Cecchi et al., "Full 3D homogenization approach to investigate the behavior of masonry arch bridges: the venice trans-lagoon railway bridge," Construction and Building Materials, vol. 66, no. 36, pp. 567-586, 2014. 

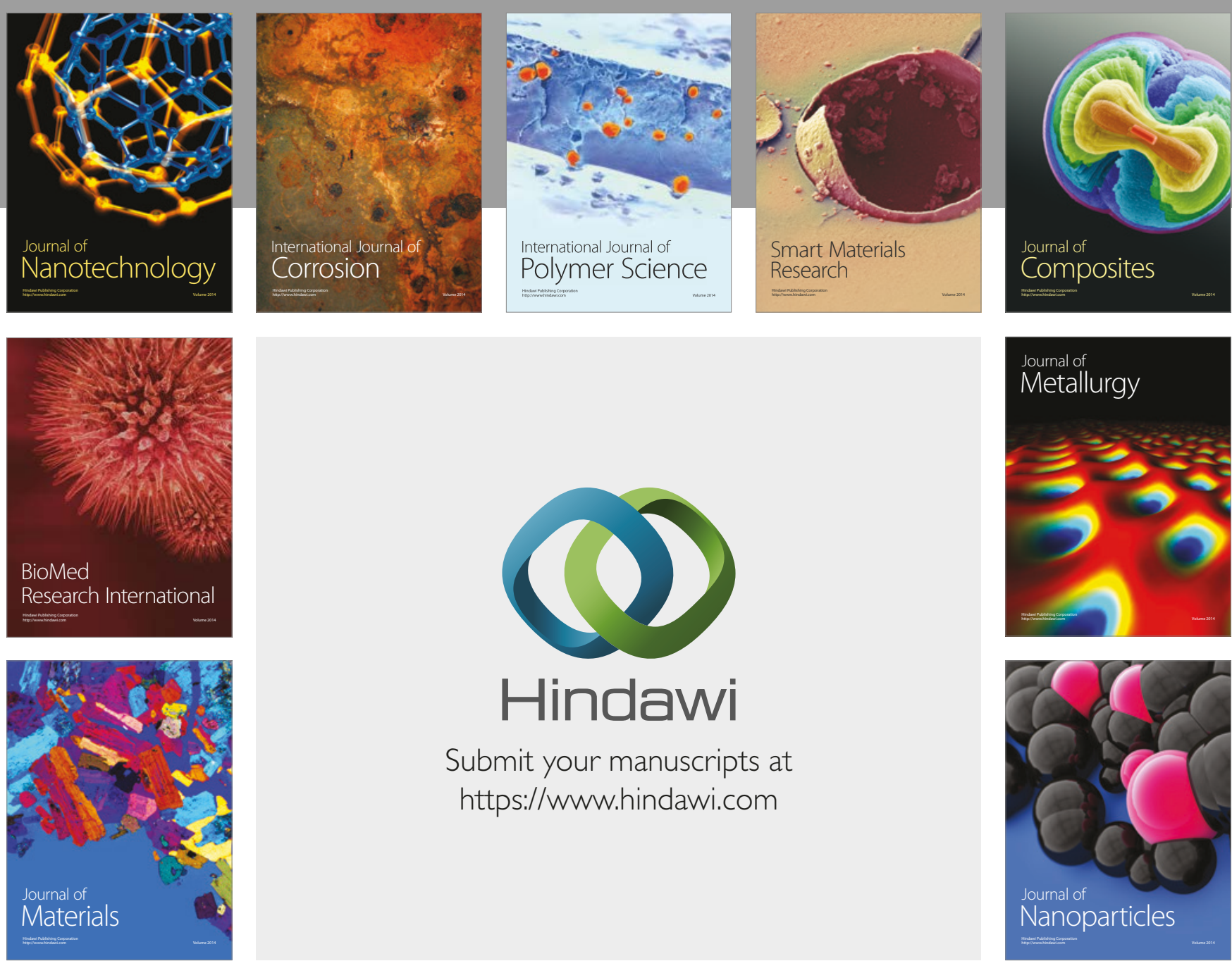

\section{Hindawi}

Submit your manuscripts at

https://www.hindawi.com
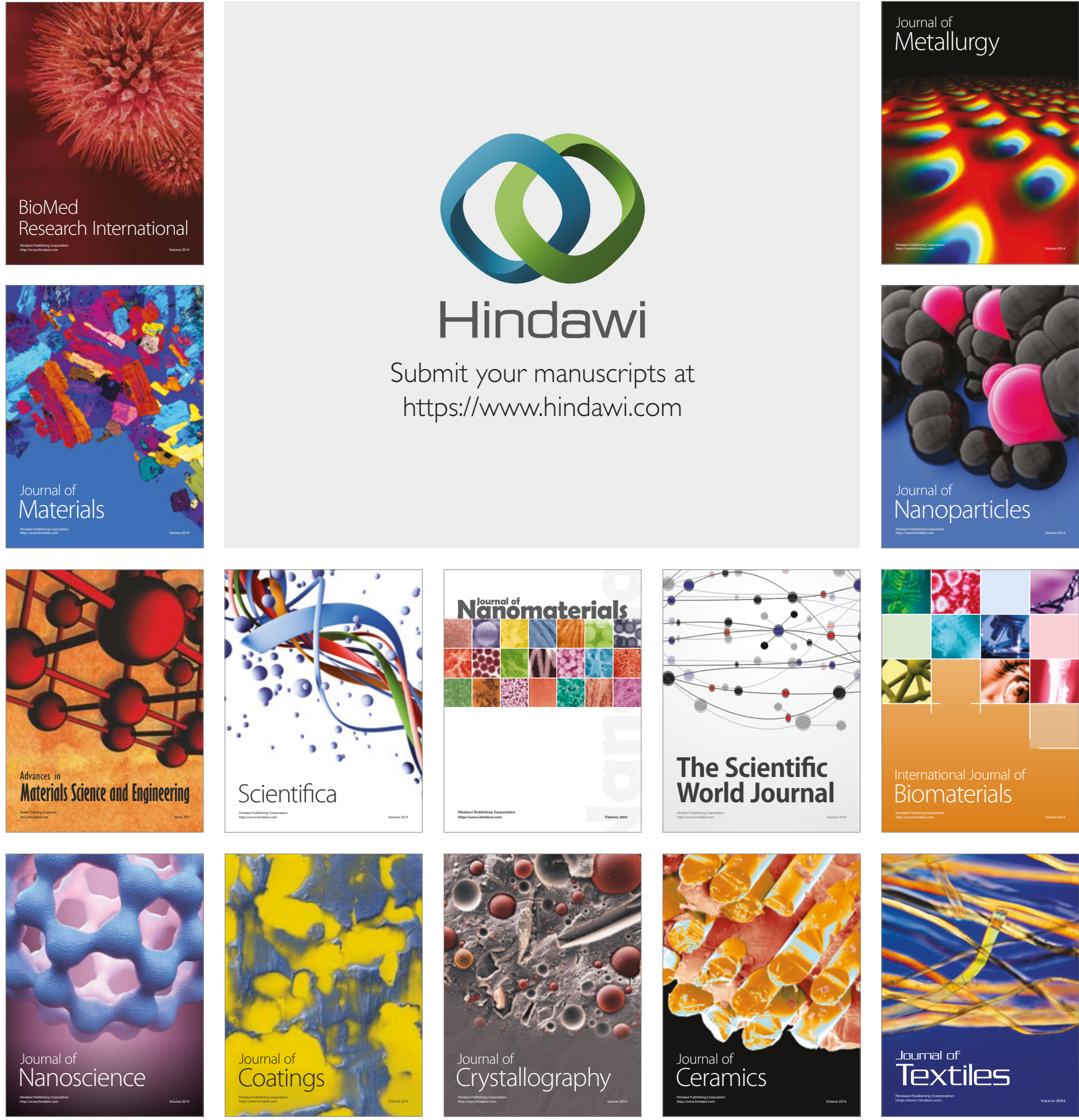

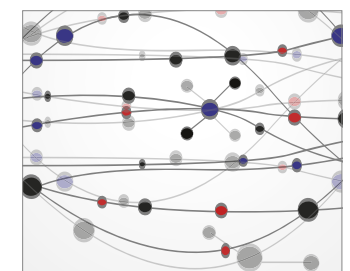

The Scientific World Journal
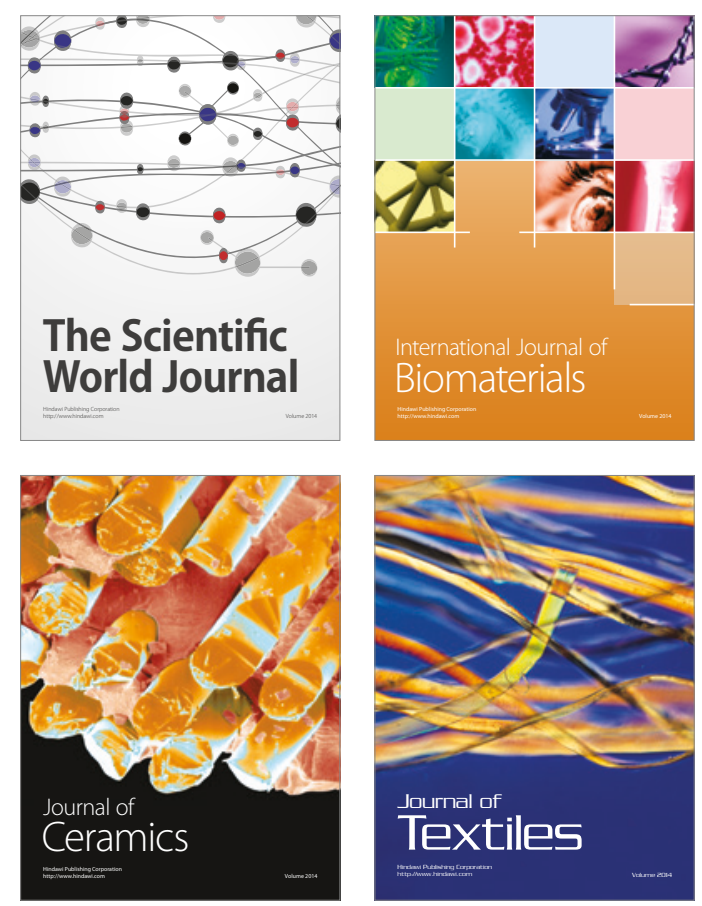